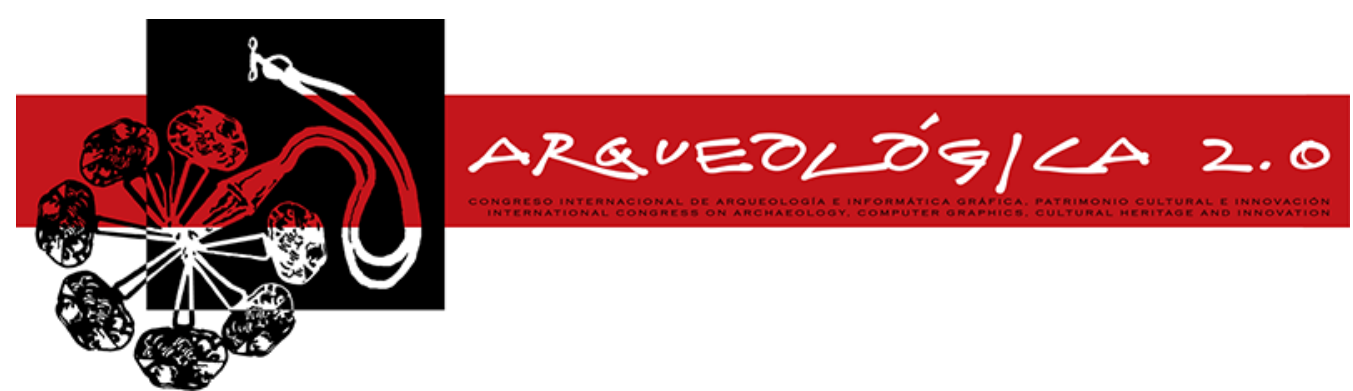

Proceedings of the $8^{\text {th }}$ International Congress

on Archaeology,

Computer Graphics,

Cultural Heritage and Innovation

'ARQUEOLÓGICA 2.0'

in Valencia (Spain),

Sept. $5-7,2016$

DOI: http://dx.doi.org/10.4995/arqueologica8.2016.3567

Received: $07 / 03 / 2016$

Accepted: 07/05/2016

\title{
KUÉLAP VIRTUAL: VIRTUALIZACIÓN DE UNA CIUDADELA PREINCA EN LOS ANDES AMAZÓNICOS DEL PERÚ MEDIANTE FOTOGRAFÍA ESFÉRICA, MODELADO 3D E IMPRESIÓN 3D
}

\author{
KUÉLAP VIRTUAL: VIRTUALIZING AN PREINCA CITADEL IN AMAZONIAN ANDES OF PERU WITH 360 \\ PHOTOGRAPHY, 3D PRINTING AND 3D MODELING
}

Esteve Ribera

CEO of Panograma Labs. Chachapoyas, Reasearcher in Centro Mallqui, Institute of Bioarchaeology, Leymebamba, Perú. eribera@panograma.net

\begin{abstract}
:
Between 2010 and 2012, under the International Cooperation for Development, a virtual archeology project was realized in Amazonian Andes of Peru. The project was carried out with collaboration from Universitat Politécnica de València (UPV) and the Agencia Española de Cooperación Internacional al Desarrollo (AECID), with archeologists taking part in Proyecto Especial Kuélap (PEK). The goal was to create a virtualization of Kuélap, an important monumental citadel constructed by the ancient Chachapoya society. The fruits of the project was the website "kuelapvirtual.com", that offers an interactive virtual visit (like street view) as well as geographical and archaeological information of interest. Furthermore, a virtual 3D reconstruction was created from blueprints, topographic data available and assistance from archaeologists. The $3 \mathrm{~d}$ digital model made the fabrication of a two prototipes: an archaeological model in scale 1:750 and a topographical model in scale 1:17500, obtained through 3D printing at the Department of Engineering Projects at Universitat Politècnica de València.
\end{abstract}

Key words: Kuélap virtual, virtual tour, spheric photography, 3D reconstruction, 3D print, Chachapoya, Peru.

\section{Resumen:}

Entre 2010 y 2012, en el marco de la Cooperación Internacional al Desarrollo, se llevó a cabo un proyecto de arqueología virtual en los Andes Amazónicos del Perú. Este proyecto fue producto de la colaboración de la Universidad Politécnica de València (UPV) y la Agencia Española de Cooperación Internacional al Desarrollo (AECID) con los arqueólogos del Proyecto Especial Kuélap (PEK). El proyecto tuvo por objeto la virtualización de Kuélap, una importante ciudadela monumental construida por la antigua sociedad Chachapoya. Fruto de este proyecto, se lanzó en la red el portal "kuelapvirtual.com": una visita virtual basada en la técnica de la fotografía esférica inmersiva (street view) con información geográfica y arqueológica de interés. Por otro lado, se realizó una reconstrucción virtual en 3D a partir de los planos y datos topográficos disponibles, gracias a la asistencia de los arqueólogos. Este modelo digital sirvió para la fabricación de dos prototipos: una maqueta arqueológica a escala 1:17500 y una maqueta topográfica a escala 1:750, obtenidas mediante impresión 3D en el Departamento de Proyectos de Ingeniería de la UPV.

Palabras clave: Kuélap virtual, visita virtual, fotografía esférica, reconstrucción 3D, impresión 3D, Chachapoya, Perú

\section{Introducción}

El presente artículo presenta los procesos y resultados del proyecto de arqueología virtual que se desarrolló entre el 2010 y el 2012 en la Región Amazonas del Perú. Este proyecto fue posible gracias a la colaboración de la UPV y la AECID con los arqueólogos del Proyecto Especial Kuélap del Gobierno Regional Amazonas (GRA), contribuyendo, a los fines de dicha entidad, en la investigación, conservación y difusión científica del sitio arquelógico de Kuélap.
Este trabajo conjunto se desarrolló en el marco de un proyecto de Cooperación Internacional (AECID - UPVGRA) que llevaba por título "Simulación virtual, difusión telemática y prototipado de Conjunto arqueológico de Kuélap". De forma paralela a esto, se desarrolló el Proyecto Final de Carrera (PFC) de Ingeniería Técnica en Diseño Industrial de la UPV por parte de E. Ribera, ejecutor responsable del Proyecto, bajo la dirección técnica de José Antonio Diego Mas. Se destaca que el proyecto ganó el premio a la mejor defensa de PFC de la Escuela Técnica Superior de Ingeniería del Diseño (ETSED) durante el curso 2012-2013. 
Finalmente, cabe señalar que uno de los alcances del proyecto fue el Convenio de Cooperación Interinstitucional suscrito por el GRA y la UPV, con el propósito de facilitar futuros proyectos e intercambios entre ambas entidades.

\section{Kuélap, complejo arqueológico monumental de la cultura Chachapoya}

Kuélap es el nombre con el que se conoce el asentamiento de élite de mayor importancia de la civilización Chachapoya en los Andes nororientales del Perú. Su construcción debió iniciarse en los primeros siglos de la era cristiana y su ocupación culminó hacia mediados del siglo XVI. Sus colosales murallas y su compleja arquitectura interior son evidencias de su función como conjunto poblacional bien organizado, que incluye recintos de índole administrativa, religiosa, espacios ceremoniales y de residencia permanente.(L.A. Narvaez 2011) (Fig.1).

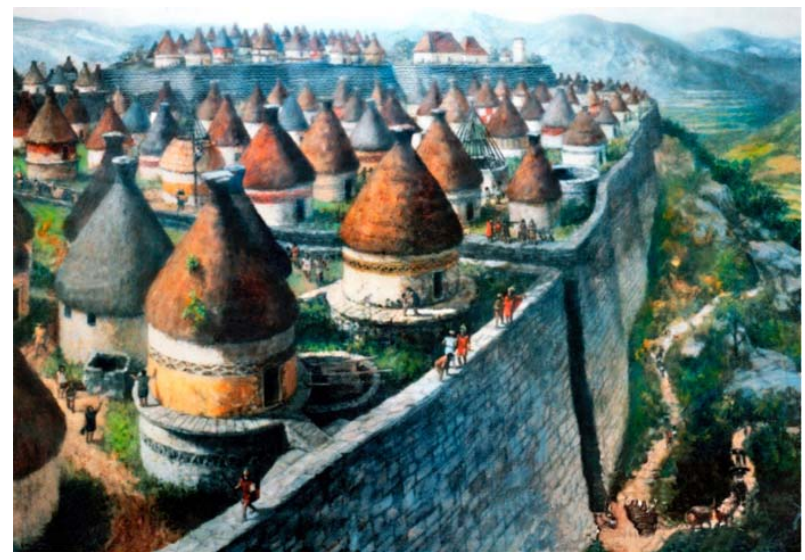

Figura 1: Recreación de Kuélap en plena ocupación. Fuente: Museo Leymebamba.

Esta importante fortaleza de aproximadamente 5 hectáreas se ubica en las coordenadas $6^{\circ} 25^{\prime} 05^{\prime \prime} \mathrm{S} 77^{\circ} 55^{\prime} 24^{\prime \prime} \mathrm{O}$, a más de $3.000 \mathrm{msnm}$, en el distrito de Luya de la Región Amazonas del Perú. En la actualidad, el sitio representa uno de los atractivos turísticos principales de la Región Amazonas, la cual recibe hasta la fecha un turismo de baja intensidad (Fig.2).

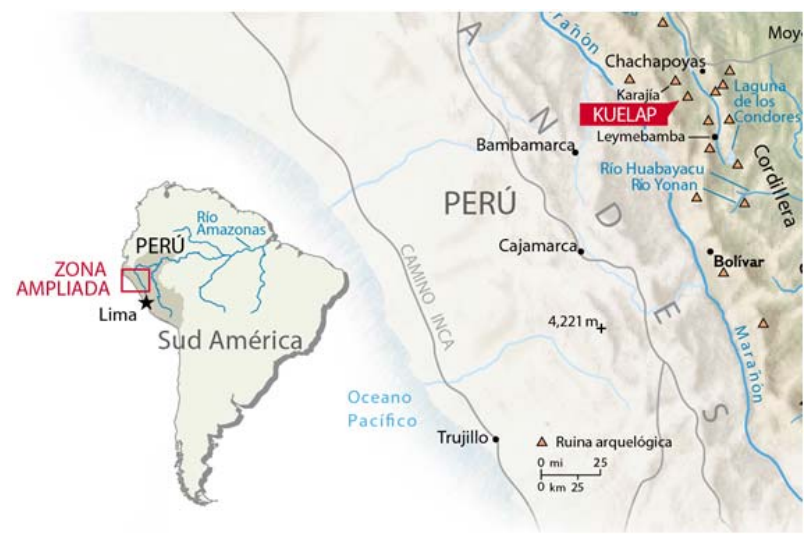

Figura 2: Infografía de ubicación geográfica de Kuélap. Fuente: Elaboración propia a partir de Infografía National Geographic 198/3: 63-81.
Cabe señalar que desde el Ministerio de Cultura del Perú y el Gobierno Regional Amazonas se han impulsado algunas campañas de excavación y conservación arqueológica del sitio, aunque de manera discontinua e insuficiente.

\section{Objetivos}

Tal y como plantea la "Carta para la Gestión y Protección del Patrimonio Arqueológico", el proyecto contempló como objetivo fundamental conseguir un equilibrio sostenido entre investigación, conservación y difusión. Cabe decir que si bien estos tres fines siempre se manifiestan de manera conjunta, en cada parte del proyecto, uno de ellos adquirió un diferente peso específico. En lo referente a la investigación, el PFC se desarrolló en colaboración con los arqueólogos y especialistas responsables de las intervenciones arqueológicas de Kuélap, quienes garantizaron resultados de gran rigor científico e integridad intelectual.

El fin de documentar el patrimonio arqueológico se materializó en la visita virtual en base a fotografía esférica de Kuélap. Esta técnica de representación virtual permitió documentar, de manera fidedigna, el estado de la Ciudadela en el preciso momento en que se obtuvieron las fotografías, con la precisión que representa una visión $360^{\circ}$ del campo visual.

Si bien la investigación y conservación (virtual) son esenciales y están siempre presentes, en la difusión es donde el proyecto puso más énfasis, debido al enorme alcance geográfico y demográfico que permite la divulgación de los resultados a través de internet.

En esta línea, uno de los objetivos logrados fue acercar el conocimiento histórico preincaico y del patrimonio arqueológico de Kuélap tanto a los especialistas en arqueología y conservación, como al gran público. De esta manera, viene fomentando el conocimiento y reconocimiento de la cultura Chachapoya como pasado histórico propio de las comunidades locales.

Por otro lado, desde el punto de vista socio-económico, el proyecto contribuyó a fomentar la promoción de una actividad turística sostenible en Kuélap, basada en el turismo cultural, que genera ingresos para la población local, y que favorece la consolidación paulatina del turismo sostenible como actividad económica alternativa a la minería y la actividad agro-pecuaria.

\section{Técnicas empleadas}

El proyecto consideró, desde sus inicios, dos productos diferenciados: simulación virtual y prototipado.

Para el primero, se tomaron en consideración las necesidades planteadas por los arqueólogos, eligiendo la técnica de la fotografía esférica inmersiva, con el propósito de ofrecer una visita virtual, a través de la red, con realismo fotográfico y como testimonio documental del estado del sitio en el año 2010.

Esta técnica se consideró la más indicada por los siguientes motivos:

- Buenos resultados gráficos

- Buena implementación en web

- Realismo fotográfico 
- Facilidad de inserción de textos y gráficos

- $\quad$ Capacidad para editar la interfaz

- Softwares asequibles

- Equipos asequibles

- Archivos livianos / carga rápida

Por otra parte, el prototipado estaba necesariamente vinculado al uso de CAD/CAM. Un equipo de topógrafos del PEK realizó un levantamiento topográfico con estación total de Kuélap. Este trabajo sirvió de base para la generación de un modelo 3D de Kuélap, sobre el que se realizó una "reconstrucción arqueológica" del sitio para mostrar su estado en plena ocupación.

\section{Etapas de ejecución}

La ejecución del proyecto se definió en 4 fases:

\begin{tabular}{c|c|} 
Fase & Título \\
\hline 1. & Fotografía esférica inmersiva \\
2. & Diseño, desarrollo y difusión web \\
3. & Modelado 3D \\
4. & Prototipado
\end{tabular}

\subsection{Fotografía esférica Inmersiva}

La fotografía esférica es una técnica que consiste en la obtención de una imagen $360^{\circ}$ del entorno (imagen equirectangular), que luego es procesada informáticamente para generar una aplicación interactiva donde el usuario puede rotar el punto de vista $360^{\circ}$ a su alrededor. Hoy en día, podemos encontrar cámaras que permiten capturar fotografías esféricas con un solo disparo, como es el caso de la Ricoh Theta o algunos dispositivos android, inexistentes en el año 2010. Sin embargo, la calidad que se obtiene con esas cámaras aún dista mucho de las cámaras DSLR (Reflex), como la utilizada en el proyecto, con un lente "ojo de pez" (Fig. 3).

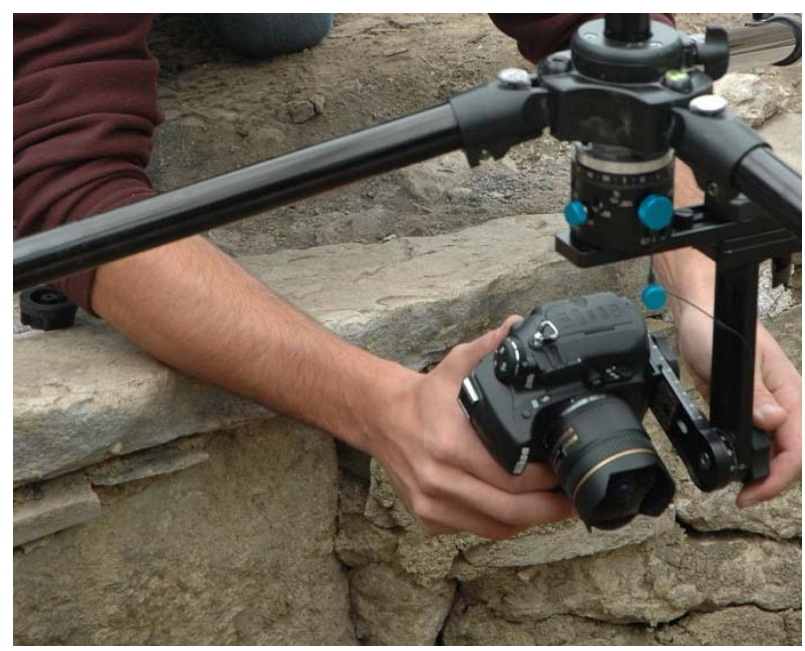

Figura 3: Fotografiando el interior de la Tumba encontrada en el Pueblo Alto de Kuélap. Foto: Marla Toyne.

\subsubsection{Cabezal panorámico}

La clave para obtener buenos resultados consistió, principalmente, en la precisión de las fotografías originales. Los panoramas equirectangulares se consigueron con la unión de varias fotografías, para lo cual fue esencial que estas estuvieran tomadas adecuadamente. Una vez realizado esto, el software encargado de la costura fotográfica (stitching) pudo realizar correctamente las uniones, evitando así, uno de los principales problemas conocido como efecto "parallax". Es decir, girando la cámara con un cabezal convencional, la posición aparente entre objetos situados en diferentes planos de profundidad varía con el ángulo (Fig. 4) con lo que se producen deformaciones o interpolaciones extrañas al unir las imágenes con la consecuente falta de definición y calidad. Para evitar esto, se utilizó un "cabezal panorámico", que permitió girar la cámara alrededor del punto nodal, también llamado "punto de pupila" o "punto de no paralaje", evitando así esta distorsión. (Fig. 5).
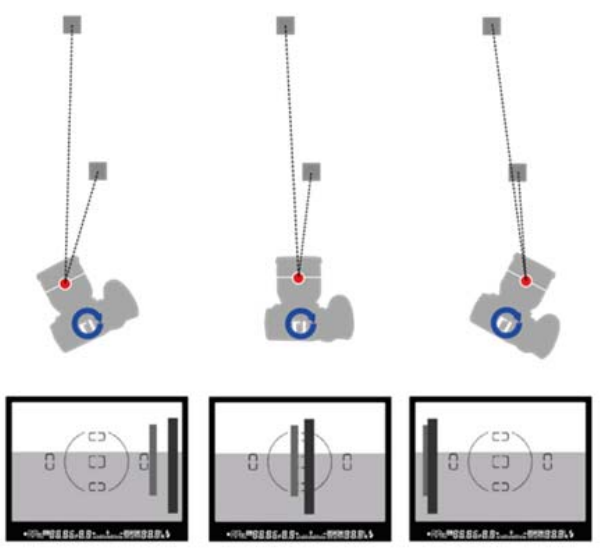

Figura 4: Rotación con cabezal convencional. Elaboración propia inspirada en Big Ben's Panorama Tutorials.

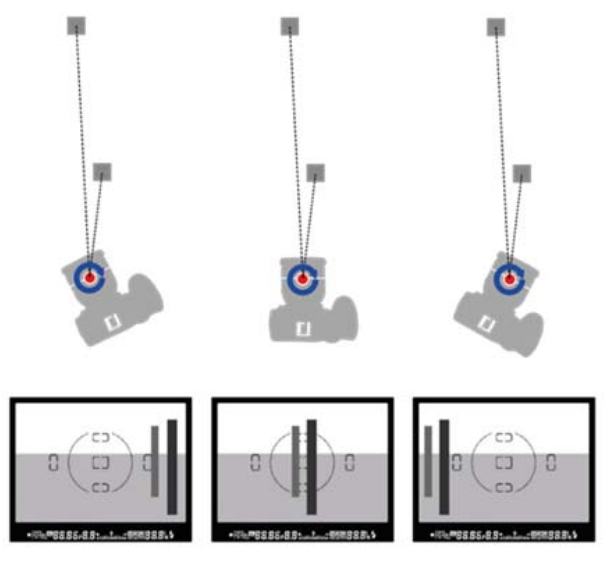

Figura 5: Rotación calibrada con cabezal panorámico alrededor del NPP o punto de no paralaje.

\subsubsection{Trabajo de campo: fotografiando Kuélap}

Conjuntamente con el equipo arqueológico, se seleccionaron los espacios de mayor interés para realizar los panoramas. Finalmente, fueron 19 los puntos elegidos, siendo estos suficientes para mostrar el conjunto arqueológico en profundidad $\mathrm{y}$, especialmente, para exhibir sitios no accesibles al visitante, como el interior del Templo Mayor o el interior de una tumba de la élite; un importante hallazgo que se produjo justo al iniciar el proyecto (Fig. 6). 


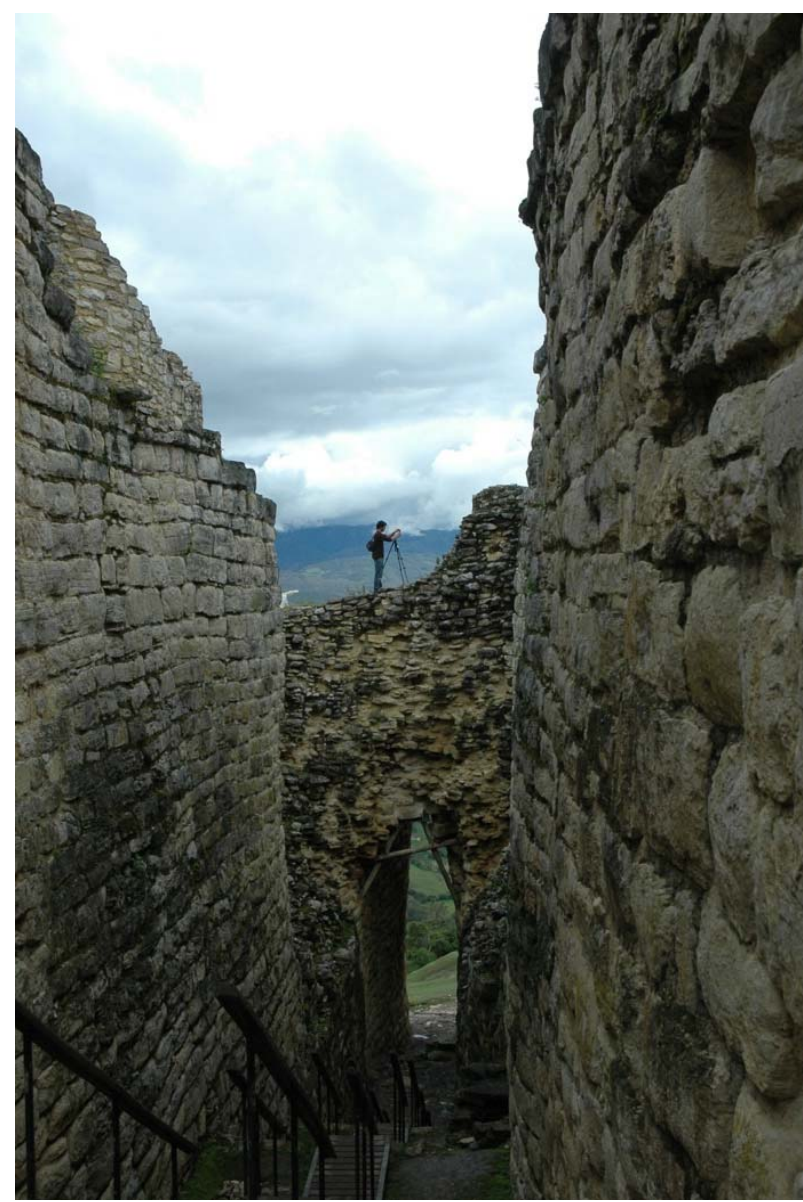

Figura 6: Fotografiando la parte superior del Acceso 1 de Kuélap. Foto: Marla Toyne.

La técnica empleada para cada panorama consistió en capturar 6 tomas horizontales (una cada $60^{\circ}$ ), más la captura del zénit. Para controlar el ángulo de giro de la cámara, fue muy útil un accesorio fotográfico llamado "rotador", que permitió definir el giro en $60^{\circ}$ y rotar así la cámara con total exactitud y comodidad.

En algunos casos, se tomaron 3 fotografías por cada posición de la cámara, haciendo uso del braketing. Esta función permitió la captura automatizada de una misma escena, variando el valor de exposición (EV), con lo que se obtuvo una secuencia escalonada de 3 exposiciones por cada imagen.

Con este método, se aseguró captar la máxima información fotográfica "en bruto" y de manera sistemática, llegando a los resultados deseados con la técnica del Hight Dinamic Range (HDR).

\subsubsection{Pocesado digital}

El hecho de combinar la fotografía panorámica con el HDR/Exposure fusion amplió enormemente el número de variables en el flujo de trabajo, ya que eran necesarias un gran número de operaciones, y la casuística, derivada del orden de ejecución y los programas a utilizar, era muy grande. Por este motivo, se consultó a especialistas en fotografía digital y se realizaron numerosas pruebas con distintos softwares y procesos hasta llegar a definir un flujo de trabajo sistemático óptimo para ser aplicado a la edición de todos los panoramas.
En este sentido, fue inestimable la ayuda aportada por el especialista en fotografía digital Guillermo Luijk a través de los artículos de su web y, especialmente, por compartir libremente el software "Zeronoise" del cual es autor y que se empleó en el proyecto.

La primera decisión a la hora de definir la metodología fue elegir si realizar inicialmentela fusión (HDR / Exposurefusion) y luego la costura fotográfica (Stitching) o hacerlo en el orden inverso. Se comprobó que las dos opciones eran válidas y se podían conseguir resultados similares, así que se prefirió hacer la fusión primero y la costura después pues resultaba más práctico.

El flujo de trabajo utilizado fue el siguiente:

- Balance de Blancos con Zeronoise

- Revelado RAW neutro con Zeronoise

- Exposure Fusion con Tufuse

- Costura fotográfica con PTgui

- Retoque fotográfico con Photoshop

- Interactividad e interfaz con Pano2vr

\subsubsection{Balance de Blancos y Revelado RAW}

El formato fotográfico RAW, que en el caso de cámaras Nikon corresponde a la extensión de archivo .NEF, es un tipo de archivo "en crudo", es decir que conserva la máxima información fotográfica de la escena tal y como ha sido captada por el sensor. Se trata de un "negativo", que requiere de un "revelado" para poder visualizarse como imagen final. Existen numerosos reveladores RAW como el Adobe Lightroom o el propio revelador de Nikon (ViewNX), pero finalmente, se prefirió emplear el programa Zeronoise porque permitía definir el balance de blancos con gran precisión y brindabacomo resultado un archivo TIFF de 16 bits en bruto, sobre el que se podía realizar ajustes de exposición, contraste y saturación posteriormente, sin perder calidad. Cabe señalar que Zeronoise utiliza internamente el revelador DCraw (programado por David Coffin), de libre distribución y gran control manual.

\subsubsection{HDR y Exposure-fusion}

EI HDR es una técnica que muchas veces se asocia a un uso artístico de la fotografía caracterizado por efectos muy llamativos, con altas saturaciones y un alto nivel de artificialidad; pero no siempre es así. Las posibilidades que ofrece esta técnica son muy variadas y también es ampliamente utilizada con el propósito de obtener fotografías naturales y realísticas, como en en el caso del proyecto que se realizó

Su uso es muy apropiado cuando existe una gran diferencia entre luces y sombras en la escena (algo común en fotografía esférica), como sucede por ejemplo, en el Templo Mayor, donde el interior está muy oscuro y el exterior altamente iluminado.

\section{Fusión de tomas con HDR (32 bits)}

Existe cierta controversia a la hora de definir el HDR. Internacionalmente, las siglas HDR suelen utilizarse para hacer referencia a la fusión de la exposición en que se genera un archivo de 32 bits en bruto que contiene un rango dinámico mucho mayor que el de las fotografías capturadas por la cámara. Este archivo tiene 
extensión .HDR y no es visualizable en el monitor del ordenador debido a su número de bits. Para ello, es necesario su compresión mediante un "mapeado de tonos", que generará un LDR (Low Dinamic Range) como resultado final. Para realizar este proceso se utilizan softwares como Photomatix o Dynamic Photo HDR, pero los algoritmos que se utilizan no suelen dar resultados muy naturales.

\section{Fusión de tomas sin HDR: Exposure-fusion}

Por otra parte, existen otros métodos como los que utiliza el programa Zeronoise o Tufuse que, estrictamente hablando, también son HDR, ya que emplean archivos TIFF de 16 bits con un rango dinámico muy superior al que la cámara es capaz de capturar. Sin embargo, en estos casos suele hablarse de "exposure fusion", para diferenciarlo del clásico HDR de 32 bits. Los algoritmos que emplean estos softwares producen resultados mucho más naturales y realísticos, por lo que parecieron más apropiados para el proyecto, eligiendo Tufuse para realizar este proceso.

\subsubsection{Costura Fotográfica (Stitching)}

Como ya se ha comentado, la proyección que utilizan las fotografías esféricas es la proyección equirectangular (también conocida como proyección cilíndrica equidistante o proyección latitud-longitud). Se trata de un tipo de proyección de una superficie esférica en una imagen plana, muy utilizada en los mapamundis para representar la tierra. Ésta se basa en la traducción directa de longitud y latitud como coordenadas cartesianas, que se ha convertido en un estándar en aplicaciones informáticas para procesar mapas globales, por su correspondencia entre píxeles y su posición geográfica.

Cabe decir que los resultados de esta proyección son imágenes distorsionadas no conformes (con distorsión en las formas y los ángulos) y no equivalentes (con distorsión en las superficies). Esta distorsión es nula en el ecuador y máxima en los polos (zenit y nadir), como se observa en la Figura 7.

El programa que se eligió para realizar la costura fotográfica fue PTGui. Este programa también permite trabajar con HDR y Exposure-Fusion, y acepta los archivos RAW de Nikon (con extensión .NEF) como imágenes de entrada, pero se prefirió realizar estas operaciones con otros softwares que permitieran tener más control sobre el proceso.
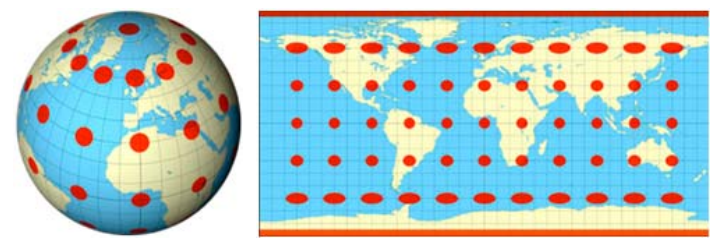

Figura 7: Proyección equirectangular plana de la superfície "esférica" terrestre, con indicadores de la deformación relativa.

\subsubsection{Retoque fotográfico}

Como último paso, para la obtención del panorama equirectangular definitivo, se realizaron algunos retoques y ajustes en Photoshop. El principal de ellos fue la corrección del nadir. Después de la costura equirectangular, siempre aparece el trípode y su sombra en la parte inferior, y una pequeña zona en blanco que no ha sido fotografiada por la cámara. Esta parte se muestra completamente distorsionada porque la distorsión es máxima en los extremos inferior y superior, con lo que la edición se hace muy difícil. Por este motivo fueron de gran utilidad los plugins de Photoshop "Super cubic filters" (Fig. 9), que permitieron la transformación del zenit y el nadir en imágenes planas sin distorsión muy fácilmente editables, que después de ser modificadas, se incorporaron de nuevo al panorama equirrectangular.

La edición consistió en reconstruir el suelo, eliminando el trípode y sus sombras, para lo cual se hizo uso de las herramientas de corrección puntual como "tampón de clonar", "pincel corrector" y "parche" (Fig. 10). Una vez corregido el suelo, se aplicó el filtro "super cubic reverse" para recuperar la proyección equirectangular (Fig. 11).

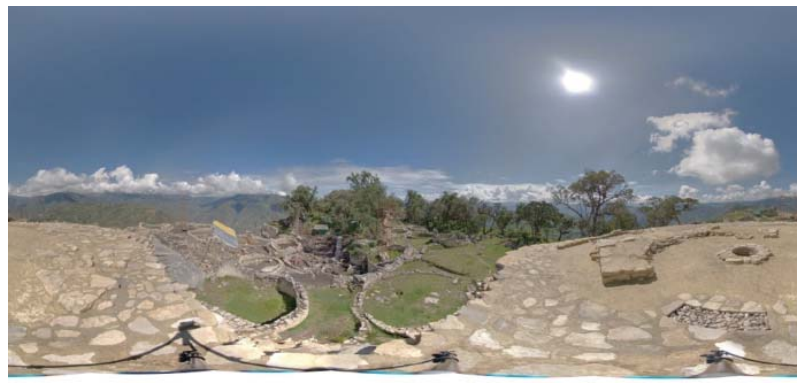

Figura 8: Panorama equirectangular original.

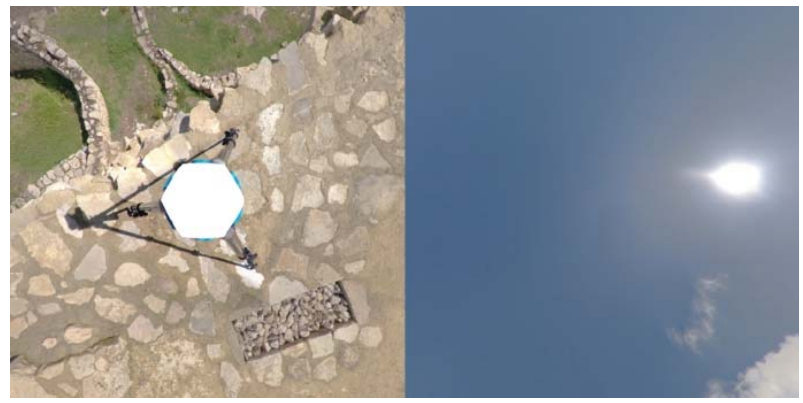

Figura 9: Proyección del nadir y el zenit tras aplicar el plugin "super cubic filter" en Photoshop.

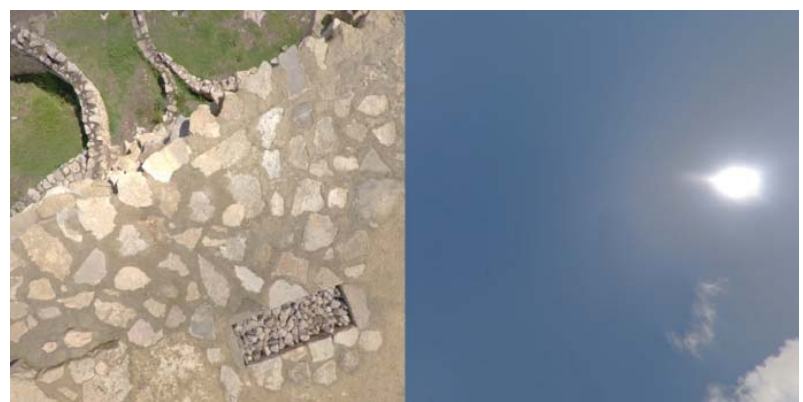

Figura 10: Resultado de la edición fotográfica local en Photoshop mediante "tampón de clonar" y "parche".

En algunos casos, en que la calibración de la cámara no fue perfecta, aparecieron pequeños fallos de costura debido al efecto parallax, que requirieron ser corregidos puntualmente. Por último, se realizaron algunos ajustes de carácter general, como definir el contraste global y la 
saturación, para obtener el panorama equirectangular definitivo.



Figura 11: Panorama equirrectangular resultante con el nadir corregido, tras aplicar el plugin "super cubic reverse"

\subsubsection{Interactvidad}

Los panoramas equirectangulares son imágenes estáticas que contienen todo el entorno esférico alrededor de un punto concreto del espacio. Desde el punto de vista fotográfico, pueden resultar interesantes por si mismas, pero en lo referente a este proyecto, lo que realmente interesó fue su interactividad e implementación web para lograr una visita virtual donde los diferentes panoramas estén conectados. Esto se consiguió mediante el programa Pano2VR; los panoramas equirectangulares (con formato TIFF o JPG) fueron utilizados como "datos de entrada", para conseguir archivos Flash, Quicktime o HTML5 interactivos como "datos de salida". Originariamente, la visita virtual se publicó en formato Flash.

Se plantea, de cara al futuro, publicar la visita virtual en formato HTML5 para permitir la indexación de contenidos por parte de Google y hacer la aplicación compatible con la mayoría de dispositivos actuales.

Para la navegación de un panorama a otro, se optó por dos métodos complementarios: la navegación por "hotspots" o puntos interactivos del panorama; y la navegación mediante "mapa de ubicación" (Fig. 12). De esta manera, el usuario tiene siempre a su alcance un mapa general que le permite saber exactamente dónde se encuentra en cada momento, y le permite desplazarse a cualquiera de los puntos interactivos de la aplicación.

\subsubsection{Graphical User Interface (GUI)}

Quizá una de las partes más complejas en la creación de la visita virtual fue la edición de su interfaz gráfica. El programa Pano2VR cuenta con un "skin editor", o editor de GUI, que se utiliza para crear un entorno gráfico con el cual controlar la aplicación. Los principales componentes en la visita virtual fueron el "panel de botones interactivos" y el "mapa de ubicación" (Fig. 13). Las funciones desarrolladas para el panel de botones fueron las siguientes:

- Girar izquierda

- Girar derecha

- Girar arriba

- Girar abajo

- Zoom in

- Zoom out

- Start/stop auto-rotación
- Pantalla complete

- Instrucciones

- Copyleft

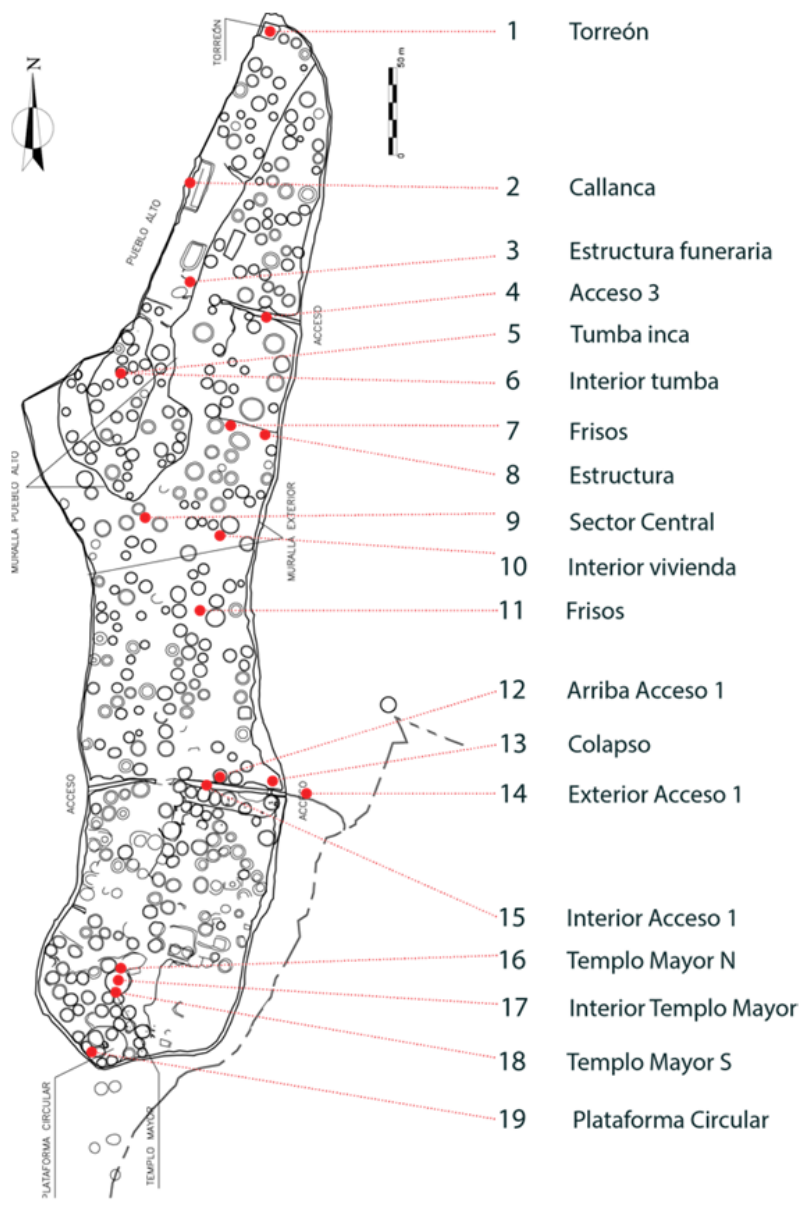

Figura 12: Puntos interactivos elegidos para la visita virtual de Kuélap. Elaboración própia. Plano: PEK - GRA.

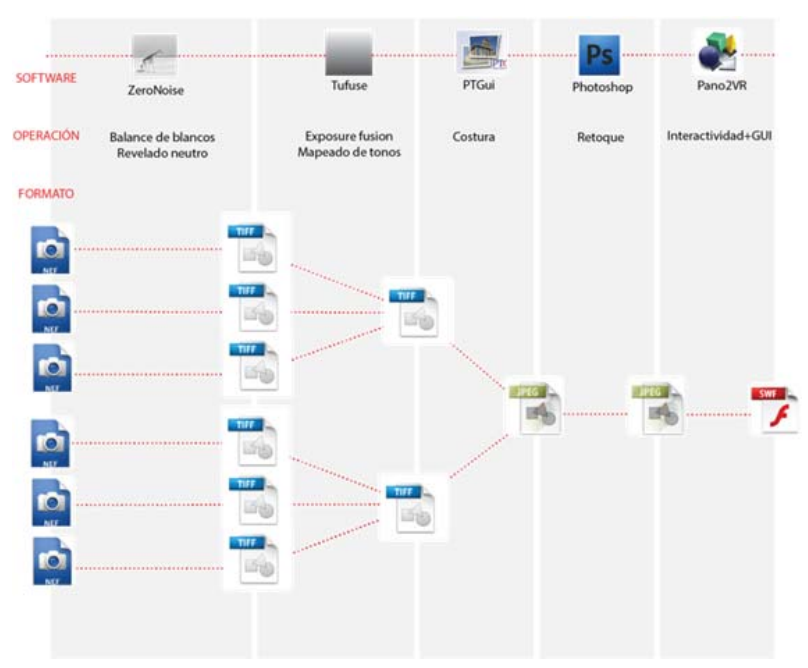

Figura 13: Diagrama simplificado del flujo de trabajo utilizado en el proyecto. Fuente: Elaboración propia.

\subsubsection{Datos y metadatos}

Con el fin de divulgar los resultados de las investigaciones realizadas en Kuélap con todo el rigor científico, se incorporaron a la visita virtual una serie de 
textos descriptivos de las principales estructuras arqueológicas de la Ciudadela, facilitados por el director arqueológico de Kuélap, Alfredo Narvaez. Estos textos se dispusieron en el lateral izquierdo de la aplicación.

Por otro lado, se consideró oportuno añadir una ventana dedicada a mostrar enlaces para ampliar la información relativa al proyecto, de forma que cualquier usuario pueda consultar el PFC, así como la presentación en Prezi del proyecto desarrollado, donde se expone toda la información contenida en este artículo de forma más ampliada.

\subsection{Diseño, desarrollo y difusión web}

\subsubsection{Diseño web}

El diseño del portal web se realizó con los requerimientos de que fuese intuitivo, atractivo, altamente visual y compatible con diferentes navegadores y dispositivos. En su desarrollo, se utilizaron los lenguajes HTML y CSS fundamentalmente, utilizando Flash para la visita virtual y JavaScript para la parte correspondiente a la aplicación de Google Earth que posteriormente se comentará (Fig. 14).

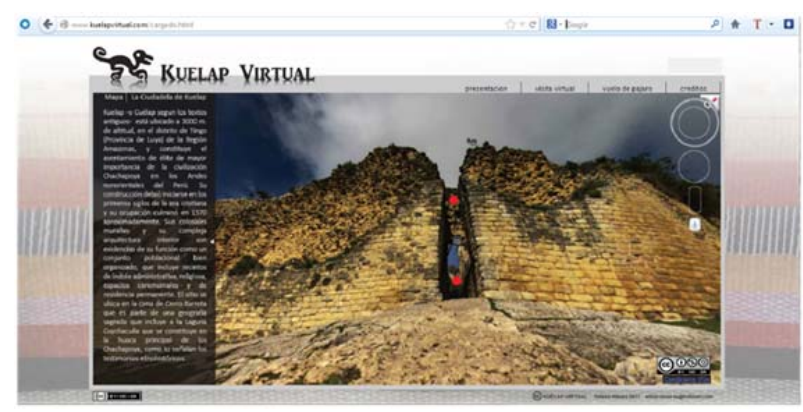

Figura 14: Versión definitiva del portal web www.kuelapvirtual.com, en la "visita virtual".

En el año 2010, empezaba a replantearse de forma global la forma en que las webs eran diseñadas, pasando de una concepción estática del diseño ,heredada de los medios impresos, a una dinámica con contenidos flexibles que se adaptan a cada tipo de pantalla y resolución. Esta nueva concepción es conocida como "diseño web responsivo". El portal web asumió este planteamiento como algo fundamental, por lo que todos los elementos de la web fueron diseñados para adaptarse a diferentes relaciones de aspecto y resoluciones de pantalla. Por otro lado, el formato de la visita virtual se basó en Flash, que es un formato que ha ido quedando desfasado con el paso de los años, ya que no es compatible con algunas plataformas actuales.

La web está estructurada en las siguientes secciones, accesibles a través del menú principal, situado en la parte superior:

- Presentación

- Visita Virtual

o Kuélap s. XI

o Kuélap s. XX

- Vuelo de pájaro
o Vista especial
o Perú-amazonas
o Kuélap de lejos

o Kuélap de cerca
- Créditos
- Info

Aplicación basada en Google Earth

Google Earth es un programa que permite navegar por un espacio virtual basado en información geográfica, presentando un globo terráqueo con diferentes niveles y contenidos de mapas geográficos (Fig. 15). Además de la versión online y el programa de escritorio, Google Earth cuenta con una API para desarrollar aplicaciones propias de gran complejidad para web. En lo relativo al proyecto, se tomó la decisión de utilizar esta herramienta para ubicar geográficamente al usuario en el espacio, mostrando diferentes niveles de zoom:

- Vista espacial (20.000 km s.n.d.m)

- Perú-amazonas (3000 km s.n.d.m)

- Kuélap de lejos (20 km s.n.d.m)

- Kuélap de Cerca (4 km s.n.d.m)

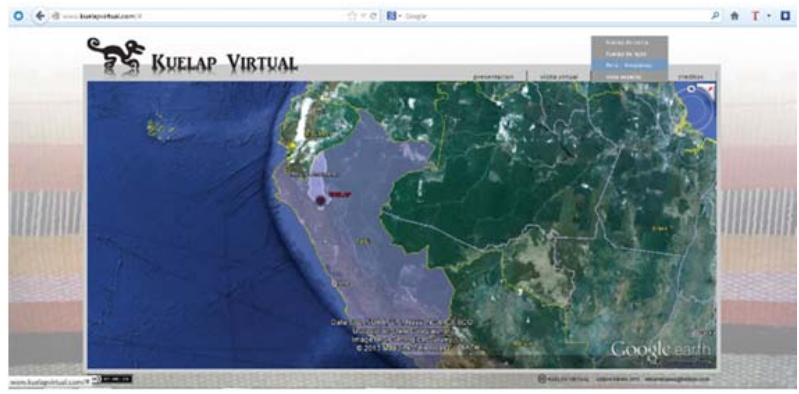

Figura 15: Versión definitiva del portal web www.kuelapvirtual.com, en la aplicación de Google Earth.

\subsection{Modelado 3D}

Modelar para el prototipado requirió de modelos con geometrías limpias, precisas y cerradas, aptas para la impresión 3D, a diferencia de lo que sucede cuando se modela con el propósito de obtener renders o animaciones. Por otra parte, el rigor científico del proyecto requería de un modelo fidedigno al original, aunque la escala del producto final determinó el nivel de detalle. En el caso del proyecto, se optó por modelar dos prototipos: una maqueta arqueológica que muestra una reconstrucción de la Ciudadela de Kuélap, a escala $1: 750$ y una maqueta topográfica que muestra el entorno circundante, a escala 1:17500. En la maqueta arqueológica se aplicó la hipótesis reconstructiva para mostrar cómo sería el sitio en su estado original hacia el sigo XI d.C.. Para ello, se contó con el asesoramiento de los arqueólogos, quienes ayudaron a definir la apariencia e inclinación de los tejados, así como la altura de los muros de las estructuras. Se decidió hacer este prototipo monocromático, por el hecho de tratarse de un modelo hipotético, mientras que la parte topográfica se realizó a todo color, con la textura de una ortofoto satelital proyectada sobre el relieve, a lo que se añadió la información toponímica extraída de un mapa físico de la zona. En el diseño de ambos prototipos, se utilizó el software de modelado 3D "Rhinoceros". 


\subsubsection{Modelado topográfico}

\subsubsection{Importación de superficie de G.E.}

En el modelado del volúmen topográfico, la geometría fue importada directamente desde el Google Earth v 4.2 con el plugin "Rhino Terrain", y la textura se trabajó independientemente. La versión 4.2 del G.E. es una versión antigua que no permite extraer ortofotos a gran resolución. En cambio, con esta version es posible importar superficies con mucha más definición y calidad que con las versiones posteriores donde esto está limitado. Por este motivo, el relieve fue importado con la versión 4.2, óptima para trabajar con el plugin Rhino Terrain.

\subsubsection{Importación de ortofoto satelital}

Con el fin de obtener una buena ortofoto, que sirviera como textura de la superficie importada, se utilizó el Google Earth Pro 6.1 que permite guardar ortofotos satelitales a gran resolución $(4800 \times 2800)$ a diferencia de la versión 4.2. En este punto, se consideró oportuno modificar la ortofoto para complementarla con la mayor cantidad de información toponímica posible, ya que además de informar sobre los nombres de montañas, quebradas, barrancos y pueblos, en la toponimia autóctona es donde más sustrato ha quedado de las lenguas prehispánicas y pre-incaicas. Como sería el caso, según algunos autores, de una hipotética lengua Chachapoya anterior al Quechua local, caracterizada entre otras cosas por el uso de las terminaciones -mal,huala, -gat y -lap, como en el caso de "Kuélap".

\subsubsection{Importación de topónimos}

Para importar la información toponímica se tomó como referencia un mapa físico de la zona, elaborado por el Instituto Geográfico Nacional (IGN) del Perú, a escala 1:100.000.

Con el programa Adobe Illustrator, y tomando el mapa como base, se reescribieron todos los topónimos en una capa nueva, conservando su ubicación original. Como último paso, se incorporó esta capa la ortofoto satelital obtenida en el paso anterior.

\subsubsection{Modelado de la reconstrucción arqueológica}

El siguiente paso a realizar fue el modelado de las edificaciones de Kuélap. En este punto, fue imprescindible la coordinación técnica con la Dirección Arqueológica de Kuélap para lograr que la hipótesis arqueológica de la Ciudadela, en su periodo ocupacional utilizada en la maqueta, contara con el rigor científico necesario.

Por el hecho de utilizar una escala de 1:750 en la fabricación de esta parte de la maqueta, las construcciones no precisaron de gran detalle ya que su tamaño real era, en su mayoría, inferior a un centímetro. De esta manera, se omitió la representación de puertas y ventanas, y la forma de las estructuras circulares típicas de Kuélap fue sintetizada y simplificada en formas geométricas básicas.

La mayor parte de las construcciones de Kuélap, exceptuando algunas estructuras singulares, presentan una planta en forma circular u ovoide; patrón arquitectónico prototípico de la cultura arqueológica Chachapoya.

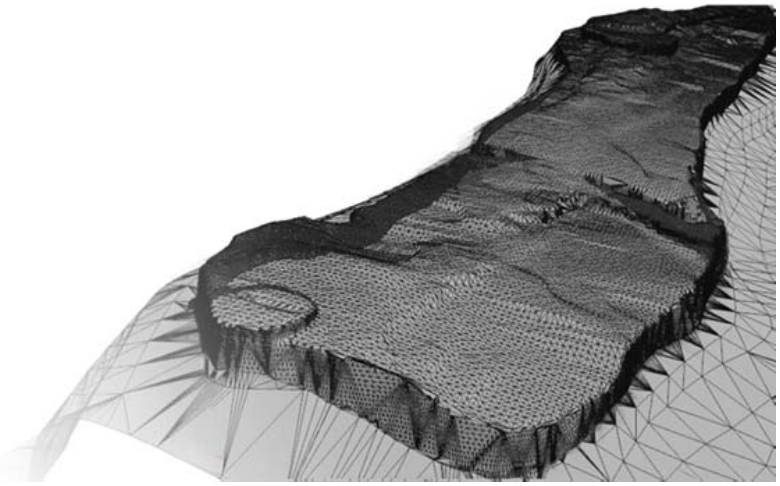

Figura 16: Malla triangular de la superficie de Kuélap sin estructuras obtenida con Rhinoceros



Figura 17: Capas del modelo topográfico: toponímia (a), ortofoto (b). Malla importada del GE (c). Modelo final dividido en 16 módulos (d)

En primer lugar, se modeló una casa prototípica, con un cuerpo cilíndrico y un tejado cónico, coronado por un pequeño tronco-de-cono invertido. Fue de gran utilidad la representación pictórica de Kuélap en plena ocupación que exhibe el "Museo de las Momias" de Leymebamba, que sirvió como referencia en el diseño del modelo. Con las curvas de nivel visibles, se fue clonando la casa prototípica y situándola en cada una de las plantas constructivas de viviendas que mostraba el plano y adaptándolas a su forma y dimensiones.

La reconstrucción presentaba, además, algunas estructuras singulares que fueron modeladas individualmente, como es el caso del Templo Mayor, el 
Castillo, la Callanca y algunas estructuras de planta rectangular pertenecientes a la época inca, última etapa de la ocupación poblacional de Kuélap.

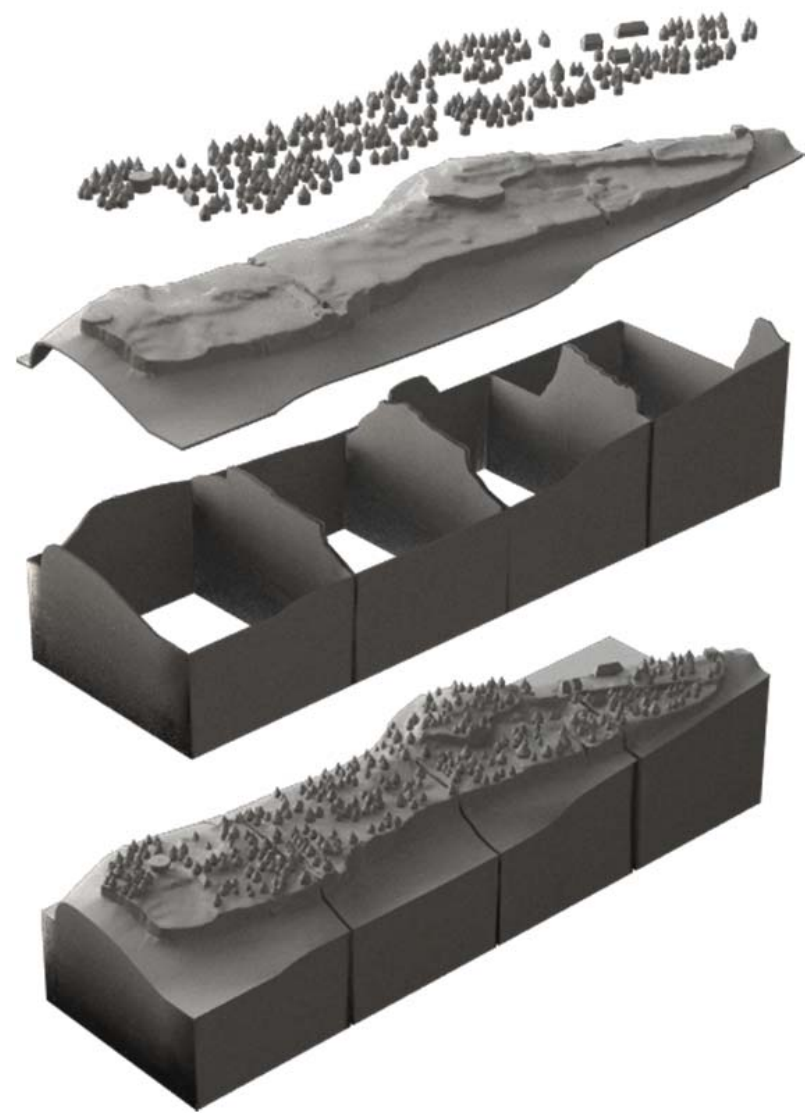

Figura 18: Capas del modelo: estructuras reconstuidas (a). Superfície modelada a partir del levantamiento topográfico(b). Soportes (c). Modelo final dividido en 4 módulos(d).

Debido a las limitaciones del área imprimible de la máquina de prototipado rápido Z-Printer $450(203 \times 254$ x $203 \mathrm{~mm}$ ), se diseñó la maqueta general en 20 módulos de 200 × $240 \mathrm{~mm}$, contando con unas dimensiones totales de $1,20 \times 0,8$ metros. La superficie del prototipo arqueológico se planteó de tal manera que en planta ocupara una área de $800 \times 240 \mathrm{~cm}$, para poder dividirla perfectamente en cuatro módulos. Tras seccionar la superficie en cuatro partes, sobre cada una de estas, se aplicó el comando del Rhinoterrain "create base", con lo que se obtuvo una base o soporte para cada módulo, tal y como se muestra en la Figura 19. Para terminar, se aplicó el comando "offset mesh" para dar grosor a la superficie correspondiente a cada módulo, generando cuatro mallas perfectamente cerradas y aptas para el prototipado rápido.

\subsubsection{Modelo Final}

Tras proyectar la ortofoto con los topónimos correspondientes al relieve importado del Google Earth, se obtuvo la superficie mapeada definitiva. Esta superficie se dividió en 16 módulos (4x4), de 200 x 240 $\mathrm{mm}$ cada uno, creando sus respectivas bases con un espesor de pared definido en $4 \mathrm{~mm}$. Todo esto se realizó mediante la opción "exportar a Z-Corp" integrada en el plugin Rhino Terrain, que permitió crear módulos directamente a partir de la malla y del rectángulo que define cada módulo en planta. Gracias a este comando, se obtuvo ,fácilmente, 16 módulos perfectamente aptos para su impresión 3D con la Z-Printer 450, economizando el material necesario para su impresión (Fig. 20).

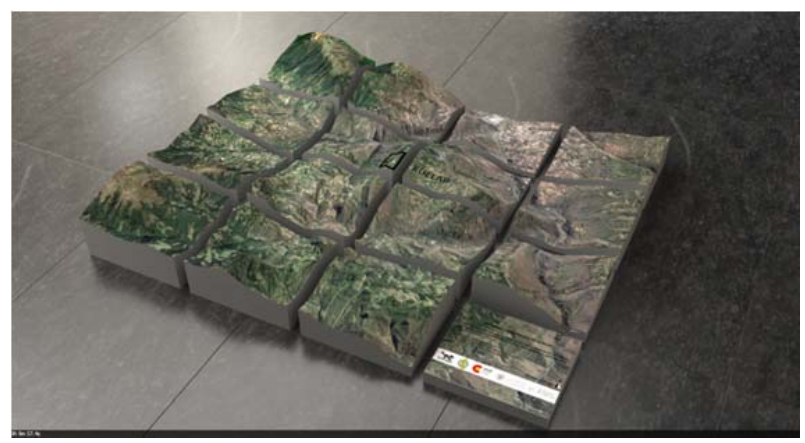

Figura 19: Render de la parte $B$ (maqueta del entorno de Kuélap) separada en sus 16 módulos.

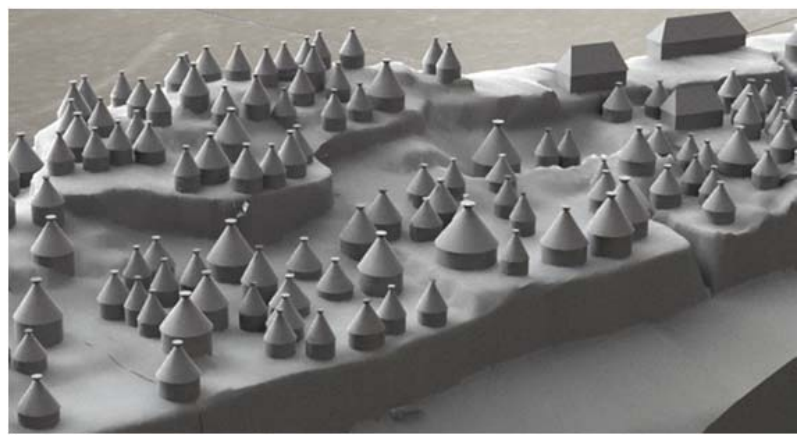

Figura 20: Modelo 3D de Kuélap con estructuras arquitectónicas incorporadas. Vista general.

\subsection{Prototipado}

\subsubsection{Hardware de impresión 3D: Z-Printer 450}

EI Departamento de Proyectos de Ingeniería de la UPV puso a disposición la máquina de prototipado rápido ZPrinter450, por lo que esta última fase se desarrolló íntegramente en dicho departamento bajo la tutela del director de PFC, José Antonio Diego Mas. Mediante este equipamiento, los módulos diseñados con Rhinoceros se materializaron en objetos físicos, que finalmente fueron sometidos a un infiltrado para aumentar su resistencia y mejorar su acabado.

\subsubsection{Software impresión 3D: Z-Print}

Mediante el software Z-Print, se validaron los modelos $3 \mathrm{D}$ antes de enviados a la máquina de prototipado (Figs. 21,22 y 23).

Después de exportar todos los módulos en formato .zpr, (formato compatible con la impresora 3D) e importarlos al programa Z-Print, todos estos fueron testeados para estimar el material necesario y planificar los tiempos de impresión. A pesar de ser una máquina de prototipado rápido, la impresión de cada módulo osciló entre las 3 y las $20 \mathrm{~h}$ de fabricación; encontrándose la media en $9 \mathrm{~h}$ $32 \mathrm{~min}$ por módulo. Por otro lado, este estudio también permitió determinar qué consumibles y en qué cantidades era necesario solicitar al distribuidor. 
El proceso de impresión por cada módulo requirió de los siguientes pasos:
a) Impresión por capas de la pieza
b) Curado
c) Retirada del polvo composite sobrante
d) Infiltrado con cianoacrilato

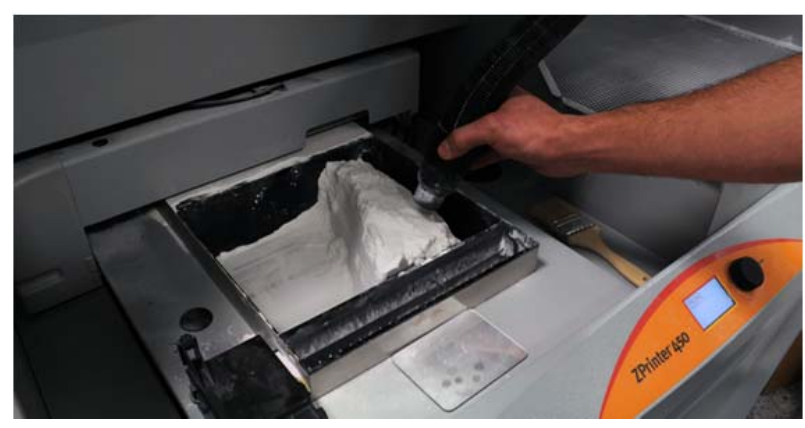

Figura 21: Retirada del polvo composite sobrante.

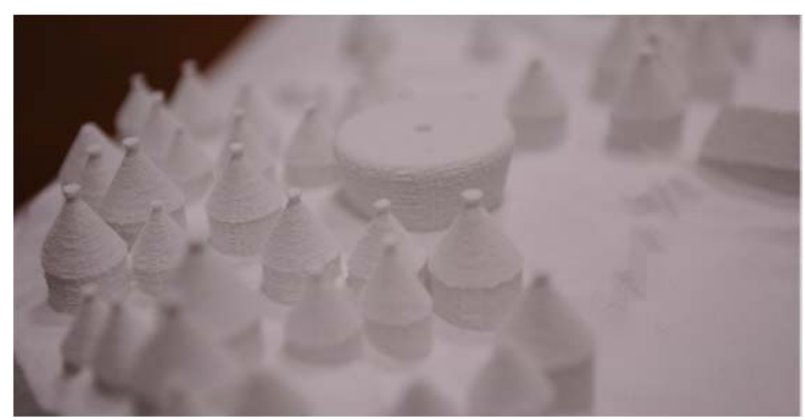

Figura 22: Detalle de la maqueta arqueológica donde se distingue el Templo Mayor.

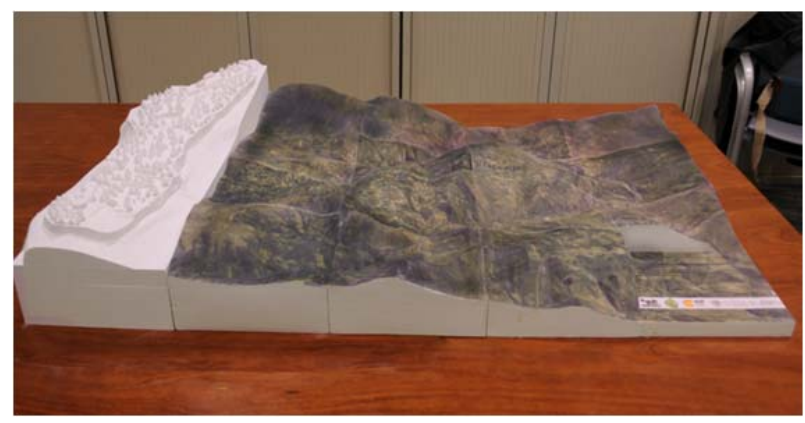

Figura 23: Prototipos arqueológico y topográfico finalizados.

\section{Conclusiones}

Se puede concluir que el proyecto logró los objetivos planteados inicialmente, ya que se consiguieron los resultados esperados y se realizó la trasferencia de los mismos a la entidad contraparte. Sin embargo, es justo reconocer que hemos encontrado muchas dificultades en el camino, que no han sido impedimento para llegar hasta el final. En esta línea, es remarcable que seis años después de iniciar el proyecto, el portal web sigue estando en activo recibiendo visitas de todas partes del mundo.

Como valoración general, se puede decir que se han conseguido resultados tangibles y útiles en cuanto a la conservación y difusión de un patrimonio de valor incalculable como la Ciudadela de Kuélap. Una de las mayores virtudes del proyecto ha sido y es su vocación comunicativa, plasmada en el enorme alcance geográfico y demográfico que permite internet.

Por otro lado, no fue posible la exhibición pública de las maquetas arqueológica y topográfica, como se esperaba, debido a los sucesivos cambios de Gobierno Regional y sus funcionarios, quienes lamentablemente no asumieron esta responsabilidad.

Finalmente, se resalta la importancia de haber alcanzado productos con una gran integridad y rigor científico, en un proyecto pluridisciplinar que ha aplicado los conocimientos técnicos del diseño en un contexto arqueológico, y con un beneficio social y divulgativo.

\section{Referencias}

BEN KREUNEN, 2000. Big Ben's Panorama Tutorials. Determining the Nodal Point of a Lens. Available: http://archive.bigben.id.au/tutorials/360/photo/nodal.html [12/02,2013].

ICOMOS, 1990. Carta Internacional para la Gestión del Patrimonio Arqueológico.

LERCHE, P. y WILTSIE, G., 2000. Lost tombs of Peru. National Geographic 198/3, pp 63-81.

LUIJK, G., 2008. Tutorial Zero Noise. Available: http://www.guillermoluijk.com/tutorial/zeronoise/index.html [13/04, 2013].

NARVAEZ, L.A., 2011. Kuélap Virtual. Available: http://www.kuelapvirtual.com/ [02/29, 2011].

VALQUI, J., 2003. Reconstrucción de la lengua chacha mediante un estudio toponímico en el distrito de La Jalca Grande (Chachapoyas-Amazonas). 